\title{
The Effect of Lavender Essential Oil Aromatherapy on the Anxiety of Endoscopy Candidates: A Clinical Trial
}

\author{
Arezoo Monfared ${ }^{1}$, Maryam Mirzaee Jirdehi ${ }^{2}$, Friborz Mansour Ghanaei ${ }^{3}$ \\ Farahnaz Joukar ${ }^{4}$, Ehsan Kazemnezhad Leyli ${ }^{5}$
}

\begin{abstract}
Background \& Aims: Endoscopy causes significant anxiety in the patients in the clinical setting. Relieving anxiety through non-pharmacological methods is an important task of nurses. Nurses take the steps to reducing the anxiety of these patients before performing diagnostic and therapeutic procedures. Aromatherapy is a complementary medicine technique used to alleviate anxiety. Aromatherapy involves the use of the essential oils of aromatic plants or other compounds to enhance health and recovery. Lavender essential oil is used in aromatherapy, which stimulates the parasympathetic system and induces relaxation by reducing the heart rate, respiration, and blood pressure. The present study aimed to assess the effect of aromatherapy with lavender essential oil on the preoperative anxiety of endoscopy candidates in Iran.

Materials \& Methods: This single-blind clinical trial was conducted at the endoscopy department of Razi Hospital in Rasht city, Iran during January 2018-August 2019. The sample population included 70 patients who were selected via convenience sampling based on the inclusion criteria and randomly divided into two groups of intervention and placebo. The inclusion criteria were the age of $\geq 18$ years, full consciousness (relative to place, time, and surroundings), willingness to participate in the study, ability to understand and speak Persian, and endoscopy of the gastrointestinal tract for the first time. The exclusion criteria were admission for emergency endoscopy, acute pain while completing the questionnaire, active mental and anxiety disorders, mental retardation, blindness/deafness, history of eczema and allergies to plants, history of migraine/chronic headaches, olfactory disorders, use of anti-anxiety drugs and narcotics, and history of severe psychological trauma (e.g., death of relatives) around the time of endoscopy. In the sampling, nine patients were excluded from the study (six cases patients due to eligibility based on the inclusion/exclusion criteria and three cases due to withdrawal), with the attrition rate considered $11 \%$ and new samples added by drawing lots. The study was registered in the Iranian Registry of Clinical Trials after the approval of the Ethics Committee of the Deputy of Research and Technology at Guilan University of Medical Sciences. The researcher referred to the research environment and attained the required permit. After obtaining written informed consent from the subjects, data were collected using a demographic questionnaire (age, gender, education level, marital status, occupation status, type of gastrointestinal disease, length of hospital stay, history of hospitalization, and smoking habits) and Spielberger state-trait anxiety inventory. The standard anxiety questionnaire consists of 20 items, which are scored based on a Likert scale (1=Very Low, 2=Low, 3=High, 4=Very High), and the total score of the anxiety scale is within the range of 2080; the minimum score of 20 shows no anxiety, and the maximum score of 80 shows the highest level of anxiety. In addition, scores 21-39 indicate mild anxiety, scores 40-59 indicate moderate anxiety, and scores 60-80 indicate
\end{abstract}

\footnotetext{
1. PhD Candidate in Nursing, Guilan University of Medical Sciences, Lecturer, Islamic Azad University, Rasht Branch, Rasht, Guilan, Iran

2. Lecturer, Department of Nursing, Guilan University of Medical Sciences, Rasht, Guilan, Iran (Corresponding author) Tel: $09113499912 \quad$ Email: mmirzaee334@gmail.com

${ }^{3}$. Professor, Subspecialty in Gastroenterology and Hepatology, Gastrointestinal and Liver Disease Research Center, Guilan University of Medical Sciences, Rasht, Guilan, Iran

4. Assistant Professor of Epidemiology, Gastrointestinal and Liver Disease Research Center, Guilan University of Medical Sciences, Rasht, Guilan, Iran

5. Associate Professor, Department of Biostatistics, Guilan University of Medical Sciences, Rasht, Guilan, Iran
} 
severe anxiety. One hour before endoscopy, the intervention group received aromatherapy with lavender essential oil, and the placebo group received aromatherapy with placebo for 30 minutes. The anxiety inventory was completed again before endoscopy. In the intervention group, two drops of $10 \%$ lavender essential oil were sprayed on a cotton ball and pinned to the collar of the patient's clothes, and the patients were asked to breathe normally for 30 minutes. In the placebo group, two drops of odorless soybean oil were used. Afterwards, the Spielberger anxiety inventory was completed again before endoscopy. Data analysis was performed in SPSS version 16 using descriptive statistics (frequency, percentage, mean, and standard deviation) and inferential statistics (independent and paired t-test) $(\mathrm{P}<0.05)$.

Results: The mean age of the patients was $47.12 \pm 16.75$ years (age range: $18-78$ years), which had no significant difference between the groups $(\mathrm{P}=0.19)$. The mean duration of the disease was $16.15 \pm 26.84$ months (range: 1 144 months). The majority of the participants were female (51.4\%), married (81.4\%), housewife (40\%), and had an undergraduate degree (58.6\%). Regarding the disease symptoms, most of the patients experienced pain $(61.4 \%)$ and indigestion and heartburn (25.7\%). In addition, $8.6 \%$ of the patients had smoking habits. However, no significant differences were observed between the intervention and placebo groups in terms of these variables $(\mathrm{P}<0.05)$. On the other hand, $45.7 \%$ of the patients reported a history of hospitalization. The results indicated that the patients had moderate anxiety in the intervention and placebo groups before and after the intervention. The mean score of anxiety before aromatherapy in the intervention group (45.91) and placebo group (50.45) was not significantly different, while after the intervention, the mean score of anxiety in the patients receiving lavender aromatherapy decreased (41.37) compared to the placebo group (49.94), indicating a significant difference in this regard $(\mathrm{P}=0.001)$. The results of paired t-test showed that the mean score of anxiety decreased significantly after the intervention compared to before the intervention $(\mathrm{P}<0.0001)$, so that after aromatherapy, the score of anxiety decreased from 45.91 to 41.37 . However, the difference was not considered significant in the placebo group $(\mathrm{P}=0.110)$, and the mean score of anxiety reduced from 50.45 to 49.49 .

Conclusion: According to the results, aromatherapy with lavender essential oil was effective in the reduction of pre-endoscopic anxiety in the patients. Due to the reduced anxiety of the patients before endoscopy, it seems that this aromatherapy method could be used before such an invasive and stressful procedure without the unwanted side-effects of chemical drugs. Considering the cost-efficiency, safety, and simplicity of this method, aromatherapy could be used as a complementary measure to reduce anxiety in patients before endoscopy. Therefore, it is recommended that randomized controlled clinical trials with control groups be performed to compare the effects of lavender aromatherapy in with various demographic characteristics and disease-related factors (e.g., history of hospitalization in patients undergoing endoscopy).

\section{Keywords: Anxiety, Endoscopy, Aromatherapy, Lavender Oil}

\section{Conflict of Interest: No}

How to Cite: Monfared A, Mirzaee Jirdehi M, Mansour Ghanaei F, Joukar F, Kazemnezhad Leyli E. The Effect of Lavender Essential Oil Aromatherapy on the Anxiety of Endoscopy Candidates: A Clinical Trial. Iran Journal of Nursing. 2020; 32(122):55-68.

Received: 13 Nov 2019

Accepted: 10 Feb 2020 


\section{تأثير رايحه درمانى اسطوخودوس بر اضطراب بيماران كانديد آندوسكويى: يك كار آزمايى}

\section{بالينى}

آرزو منفرد'، مريم ميرزايى جيردهى '، فريبرز منصور قناعى'، فرحناز جوكارعَ، احسان كاظم نزادليلى

زمينه و هدف: يكى از موقعيتهاى اضطرابآور براى بسيارى از بيماران در محيطهاى بالينى، آندوسكويى است. رايحهدرمانى يكى از روشهاى طب

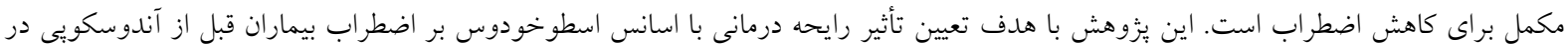
ايران انجام شد.

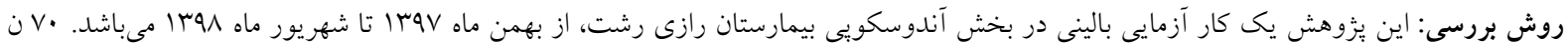

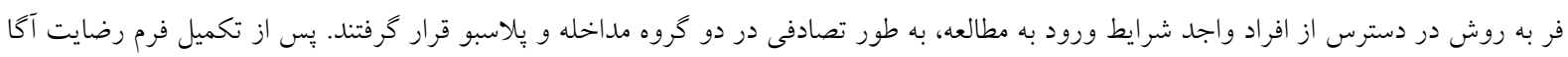

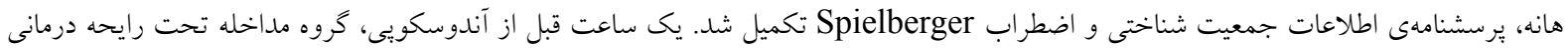

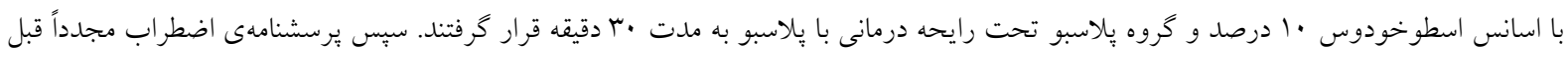

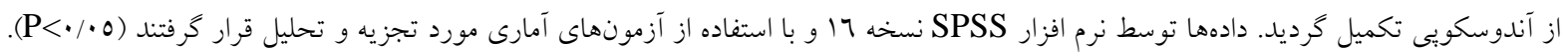
يافتها: نتايج حاصل از مطالعه نشان داد ميانكين سنى افراد شركت كننده در مطالعه 17/V0

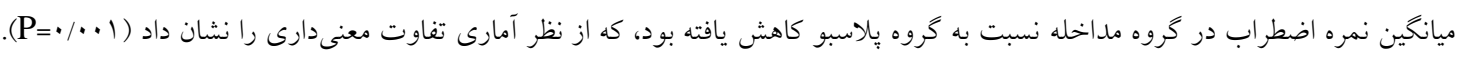

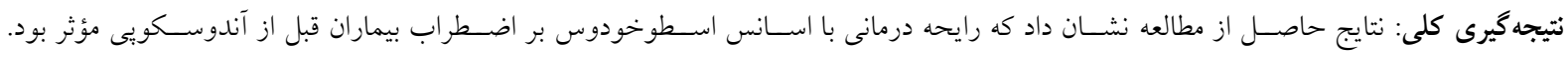

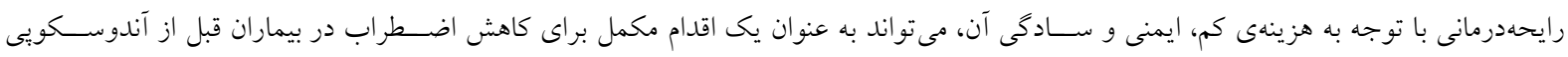
استفاده خردد.

كليد وازهها: اضطراب، آندوسكويى، رايحه درمانى، روغن اسطوخودوس تعارض منافع: وجود ندارد. تاريخ دريافت: تان

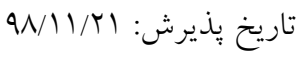

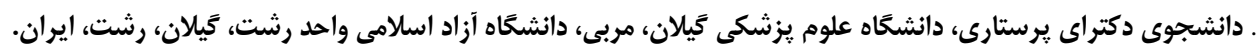

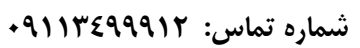

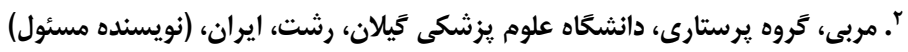
Email:mmirzaee334@gmail.com

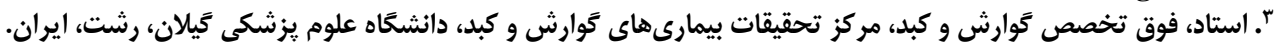

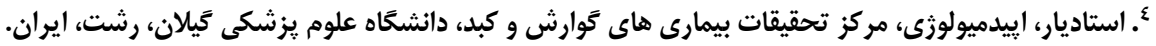

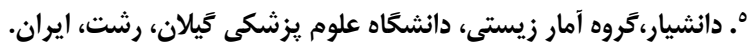




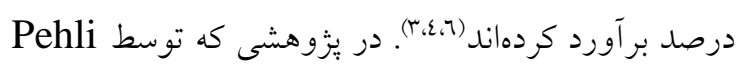
مقدمه

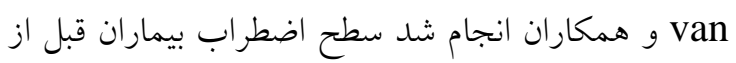

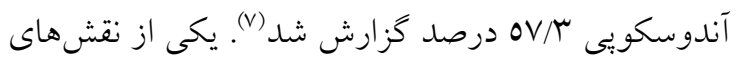
يرستار كمك به از بين بردن اضطراب است. يرستاران

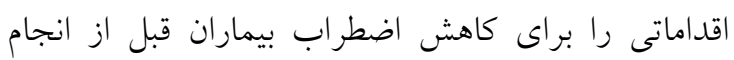
روشهاى تشخيصى و درمانى انجام مىدهند. براى مثال

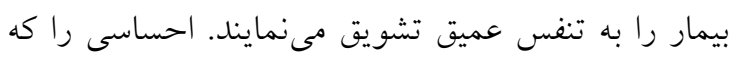
بيمار حين انجام روشهاى تشخيصى و درمانى خواهد

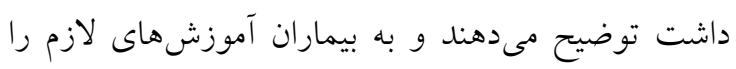

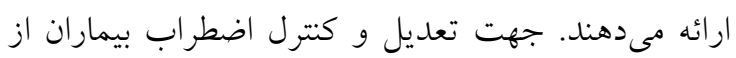
روشهاى دارويى و غيردارويى مختلفى استفاده مىشود.

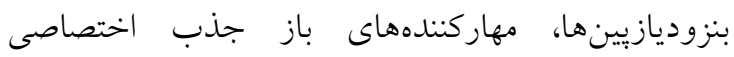

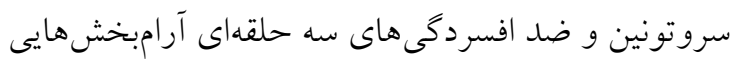
هستند كه براى كاهش اضطراب مورد استفاده قرار

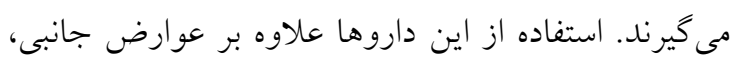

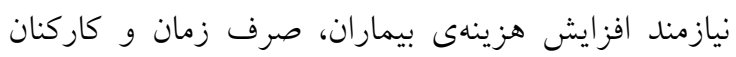
بيشتر براى مراقبت و تحت نظر قرار دادن بيماران

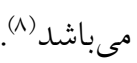
با وجود داروهاى ضد اضطراب مختلف، تعداد زيادى از

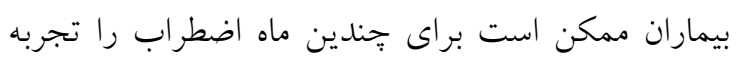

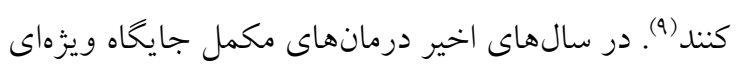

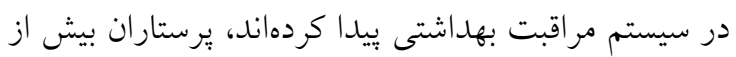

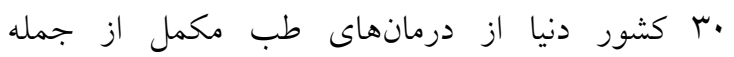

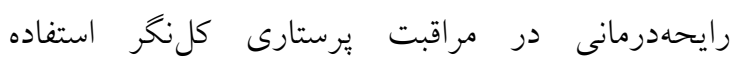

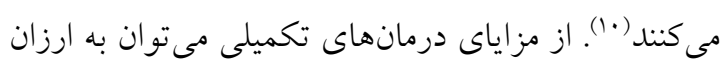

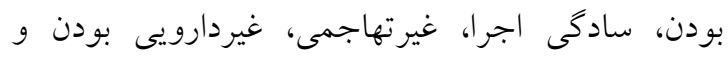

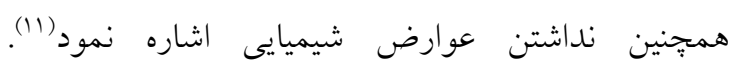
رايحهدرمانى يا آروماترايى دانش استفاده از اسانس روغنى تصني خياهان معطر يا ساير تركيبات ( odorant, aroma, (fragrance, or flavor و بهبودى است(r). رايحهدرمانى از جمله موارد درمانى

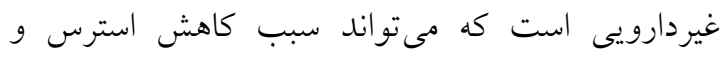

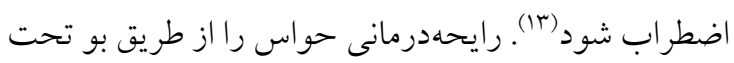

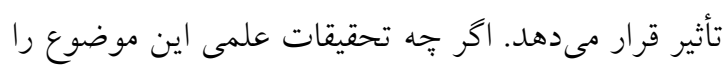
تشخيص به موقع اختلالات كوارشى جهت درمان و ميشكيرى از عوارض از اهميت بسز ايیى برخوردار است (1).

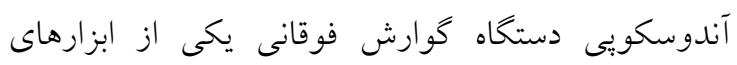
تشخيصى اصلى جهت ارزيابى و بررسى مجراى دستخاه

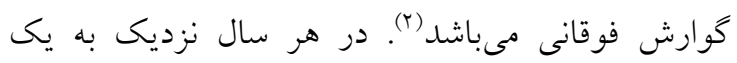

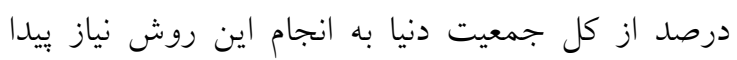

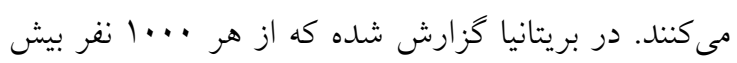

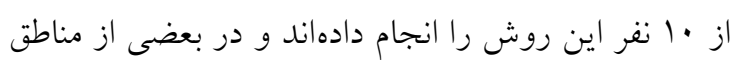

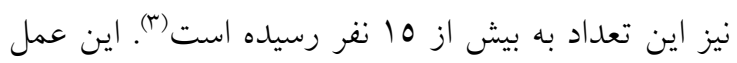

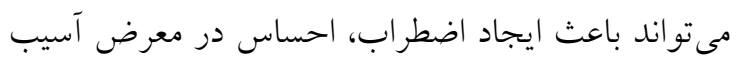

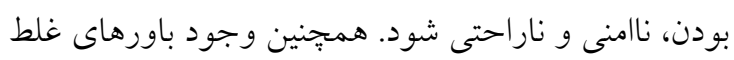
از جمله بروز درد، امكان خفكى يا تشديد نخرانىهاى

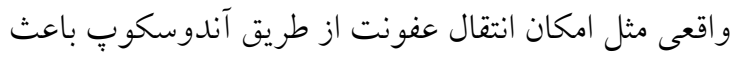

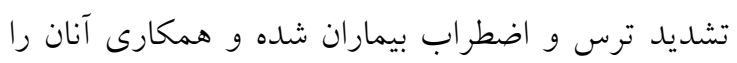

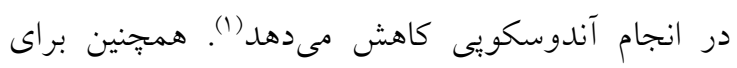

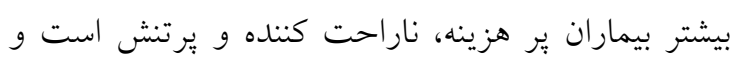

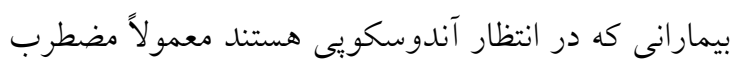
و نكران هستند. اين اضطراب ممكن است در نهايت منجر به اجتناب بيمار از انجام آندوسكويى شود (ع).

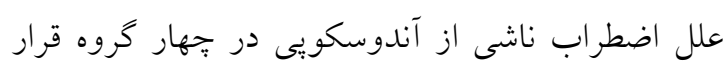

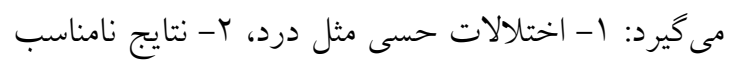

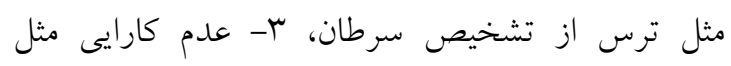

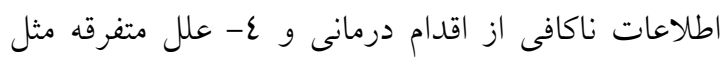

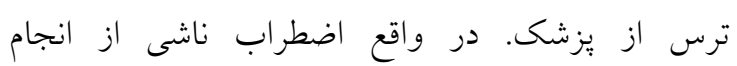
آندوسكويى يك مشكل جدى در اين مراجعه كندأنان مىباشد. شدت بالاى اضطراب مى تواند باعث عدم انجام

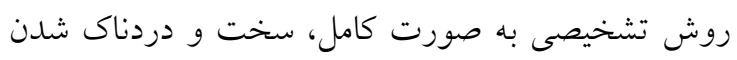

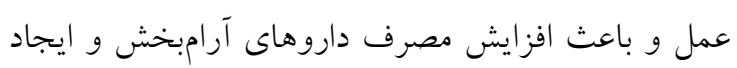

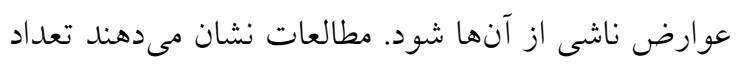

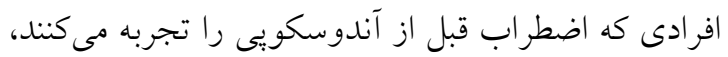
بالا است و توصيه مىشود براى كاهش ترس و و نخرانى

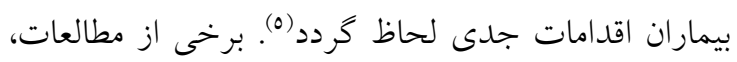

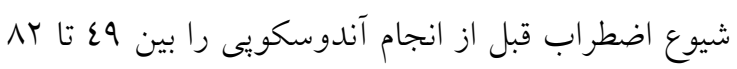


بيشتر شواهد براى حمايت از اثرات جسمى و روانى رايحه درمانى با اسطوخودوس ضعيف است و نياز به مطالعه بيشتر و با كيفيت ترى وجود دارد (rr).

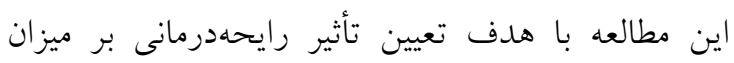

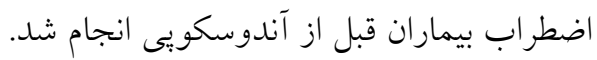

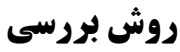
اين مطالعه از نوع كارآزمايى بالينى است كه در مركز

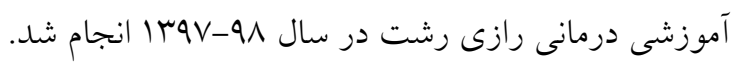

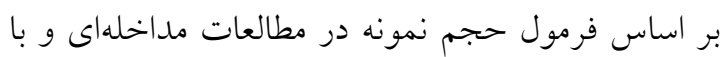

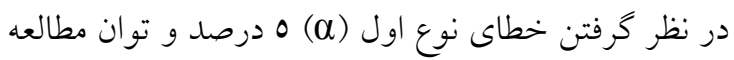

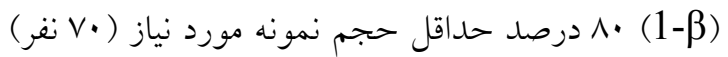

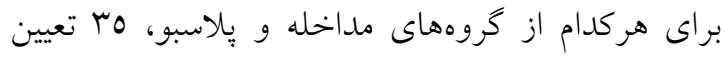
شد(1)(شكل شماره 1). تمامى اقدامات از جمله تكميل

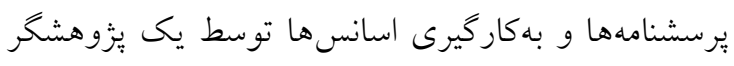

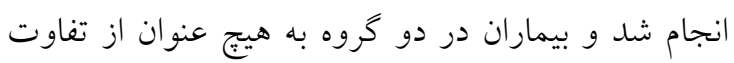
كروههاى مورد مطالعه مطلع نشدند و مطالعه يكى سوكور

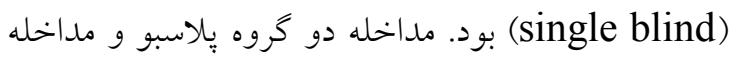

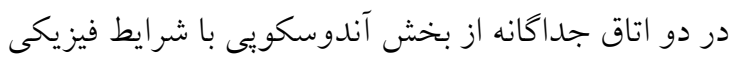
(نور، دما، رطوبت، تهويه و..) يكسان و بدون ارتباط با هم

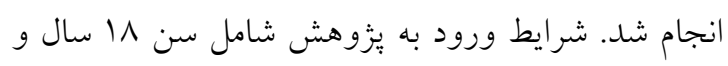

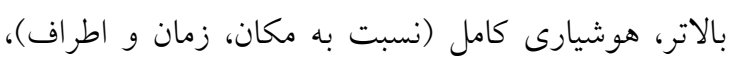

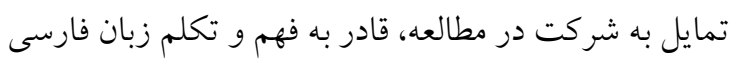

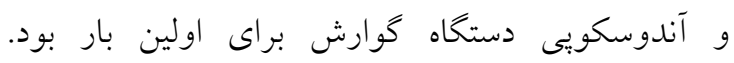

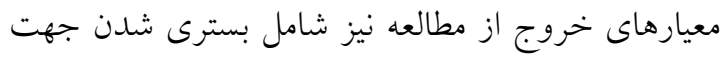

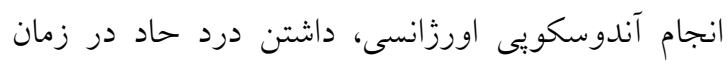
تكميل برسشنامه، داشتن بيمارى فعال روانى و اضطر ابى، داشتن عقبماندكى ذهنى، نابينايى و ناشنو ايى، سابقه اخزما

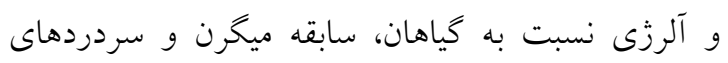

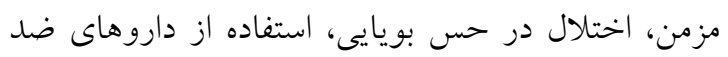

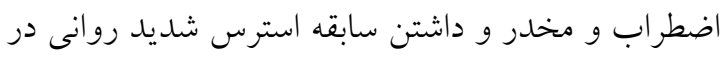
حوالى زمان آندوسكويى (مثل مرك نزديكان) بود (Yع.ro).
به طور .” درصد ثابت نكردهاند. اسطوخودوس

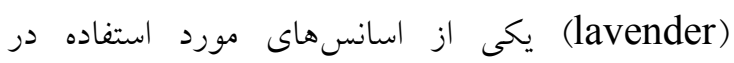

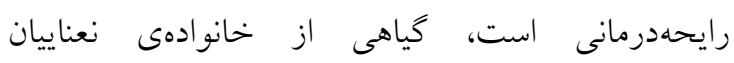
و و بسيار معطر است(ramiaceae)

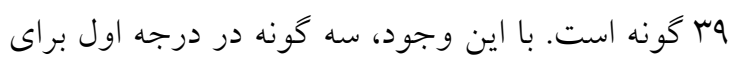

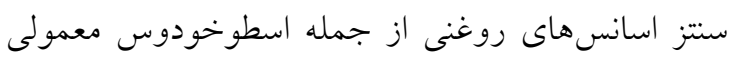
(Lavandula angustifolia)، اسطوخودوس سنبل اسنبله (L. latifolia)

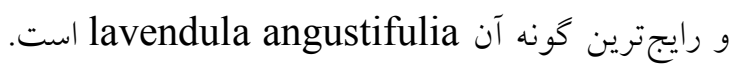
اين كياه عمدتاً براى توليد اسانس روغنى اسطوخودوس ان وس

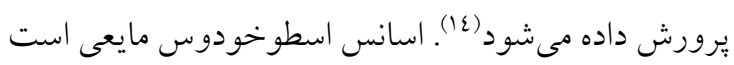
با رنخ زرد مايل به سبز كه داراى بوى مطبوعى است. ليناليل استات (Linalyl acetate) و لينالول (linalool)

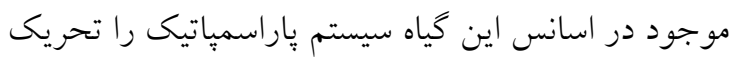

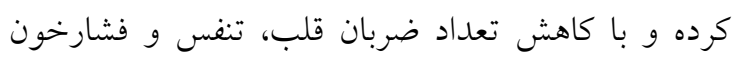
موجب آرامش مىشود (10).

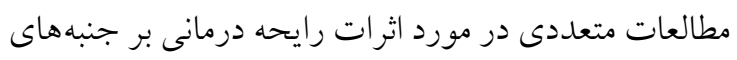

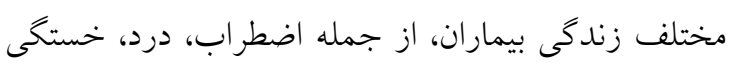

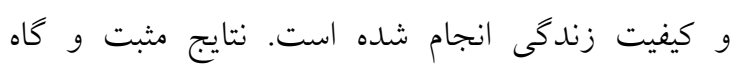

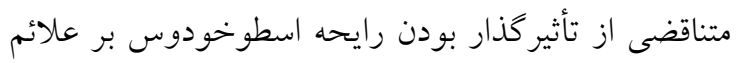

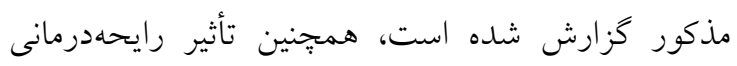

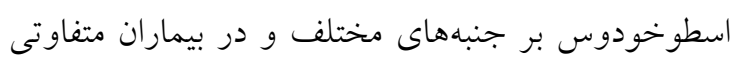

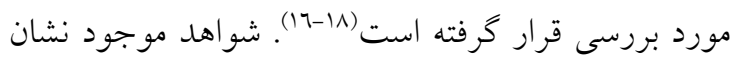

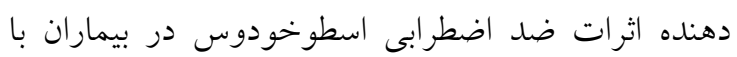
شرايط زمينهاى مختلف است. در اين مطالعات از راههاى مختلفى براى تجويز اسطوخودوس براى اضطراب از جمله ميله

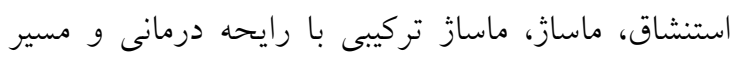

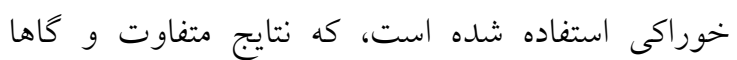

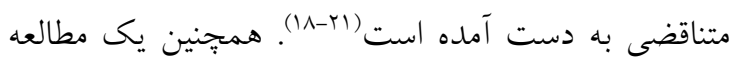
فراتحليل در بررسى تأثير اسطوخودوس نشان داد كه آنه

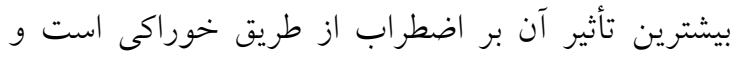

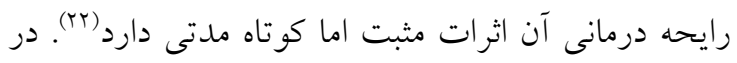
حالى كه يك مطالعه مرور نظام مند بيان كرد كه كيفيت 


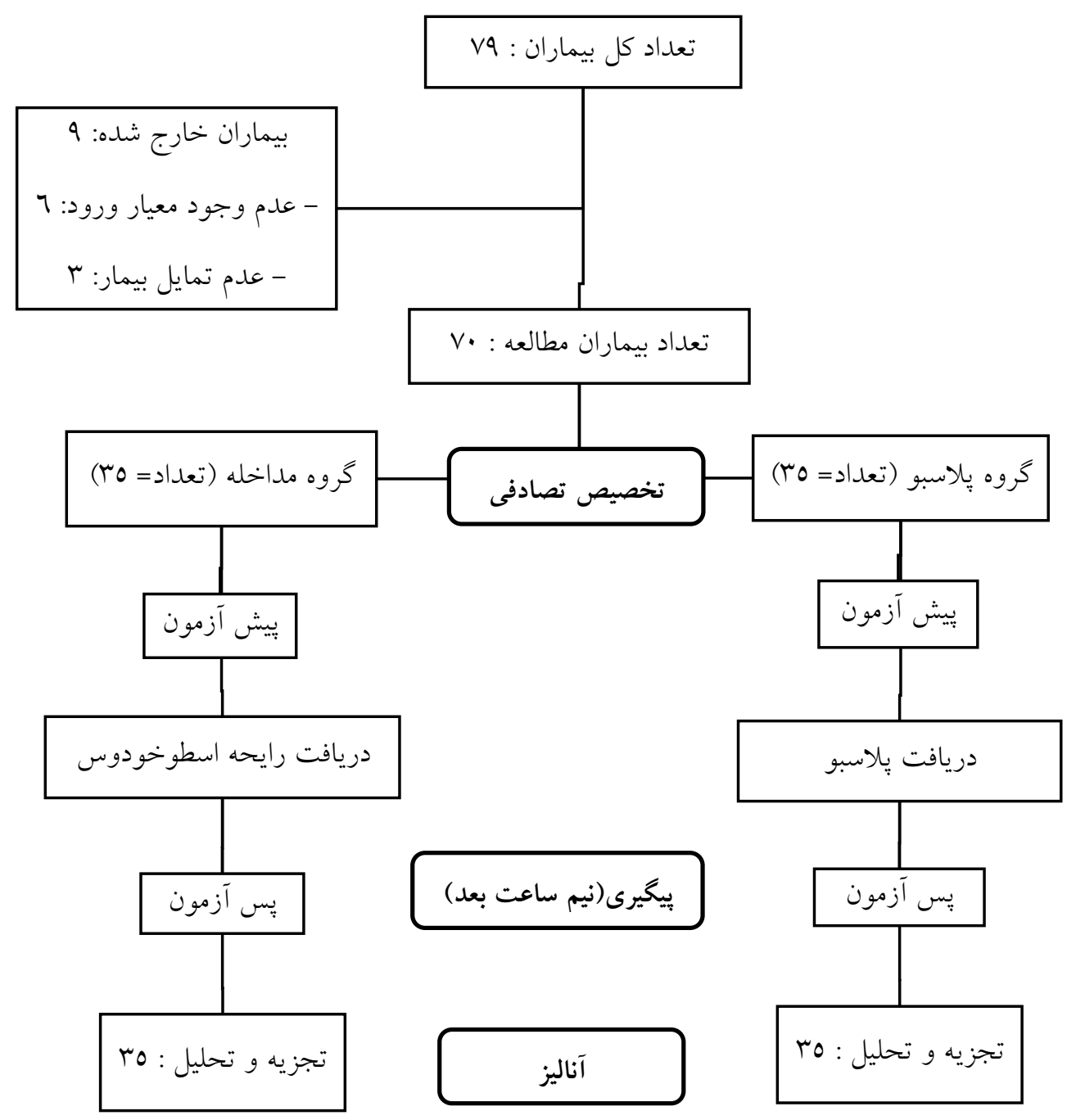

تصوير شماره (: فلو جارت CONSORT براى مطالعه

يرسشنامه اضطراب آشكار شامل ·r سؤال است كه احسا سات فرد را در لحظه و زمان بِاسخكويى، ارزشيابى مى كن إنى د. اضطراب آشكار با مقياس ليكرت كه شامل كزينه آناى 1

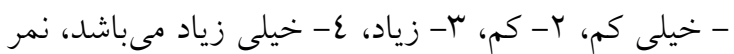

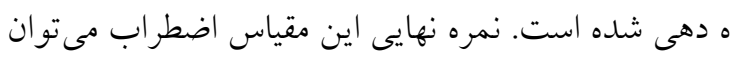

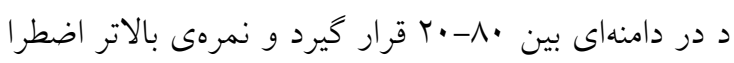
ب بيشتر را نشان مى دهد. در مورد سؤالات مثبت (سؤالا

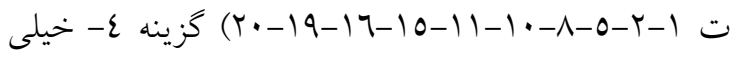
كم، ؟- كم، ז- زياد، ا- خيلى زياد و در رابطه با سؤالات منفى (سؤات ب- r-
كروه مداخله بيمارانى بودند كه با روغن كَياه اسطوخودوس و گروه دوم بيمارانى كه با دارونما (روغن سوياى بدون بو) رايحهدرمانى شدند. دادهها از طريق مصاحبه و با استفاده از يرسشنامه

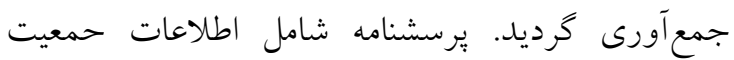
شناختى بيمار (سن، جنسيت، سطح تحصيلات، وضعيت

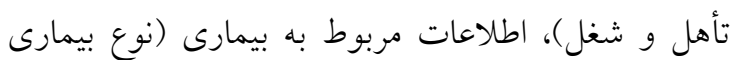

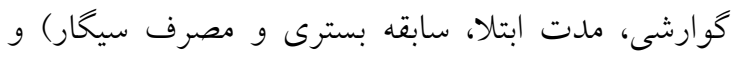

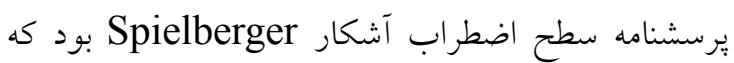
يكى ابزار معتبر است (T7). 
مستمر، (نمونههايى كه در زمان حضور يزوهشك براى

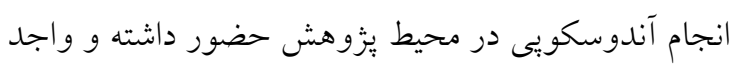

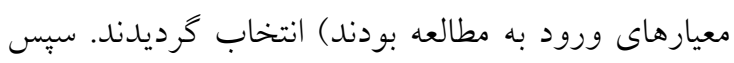
تخصيص تصادفى نمونهها در دو گروه مداخله و گروه

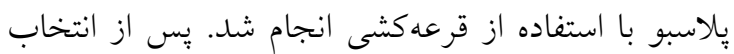

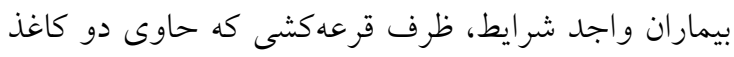

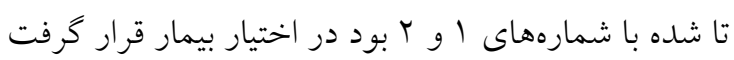
تا يكى شماره را به صورت تصادفى خارج نمايد، آن شماره

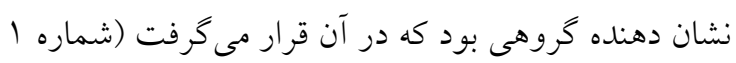

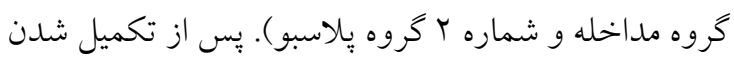

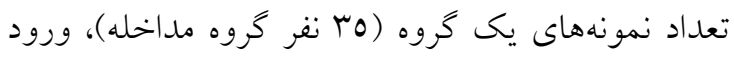
نمونهها با همين روش قرعه كشى براى گروه باقى مانده

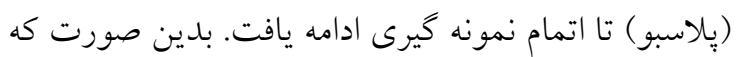
اخر بيمارى طى قرعه كشى بين دو شماره ا و و ب، شماره

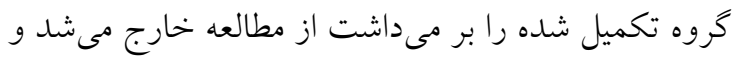
قرعه كشى با بيمار بعدى ادامه مى يافت، تا اين كه تعداد

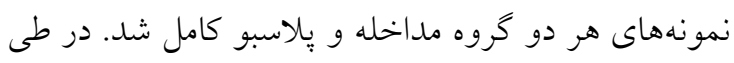

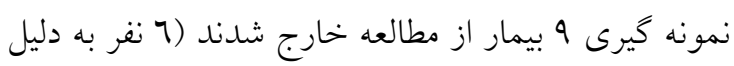

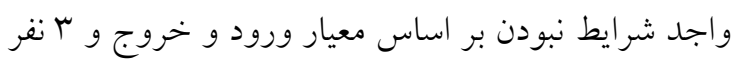

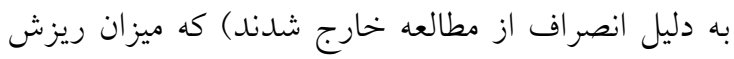
11 ادرصد بود و نمونههاى جديد با روش قرعه كشى اضافه

يّ از تكميل قسمت اطلاعات جمعيت شناختى و

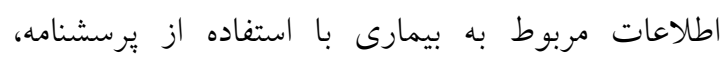

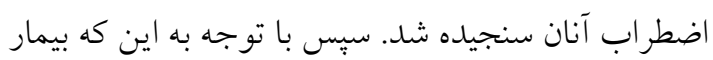

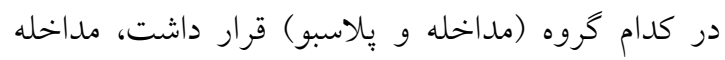
بدين صورت انجام گرفت كه يك ساعت قبل از انجام

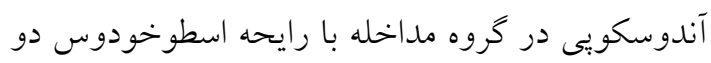

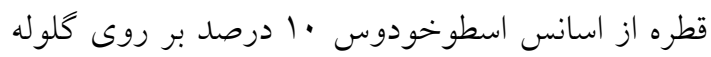
ينبهاى جكانده شد و به وسيله سنجاق به يقه لباس بيمار

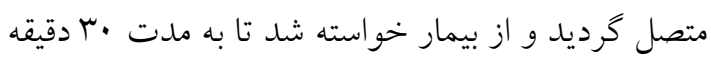
به صورت عادى تنفس نمايد. در مطالعات مختلف اشاره

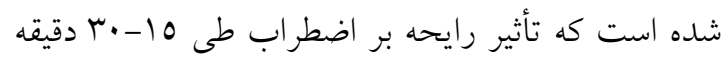

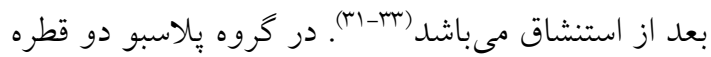

كزينه ا- خيلى كم، r- كم، r- زياد، ع- خيلى زياد است

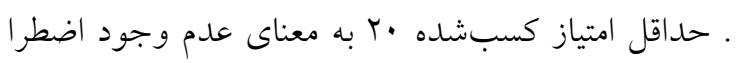

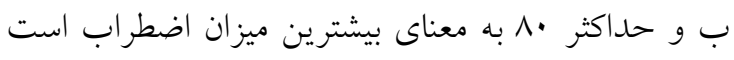

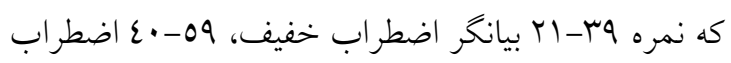
متوسط و نمره •^-••7 نشاندهنده اضطراب شديد است.

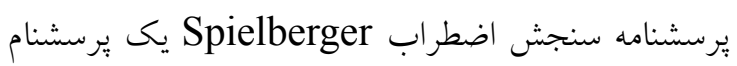

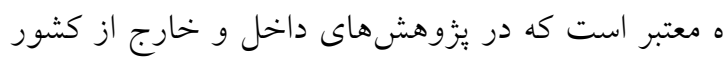
به ميزان وسيعى به كار رفته است و اعتبار علمى آن مورد

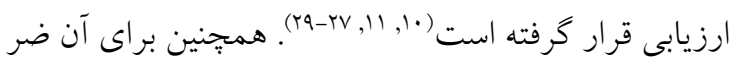

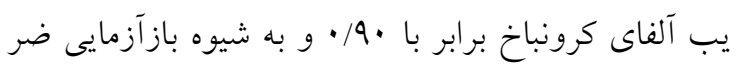

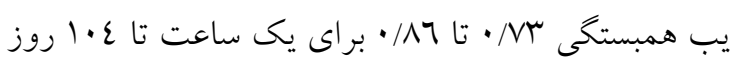

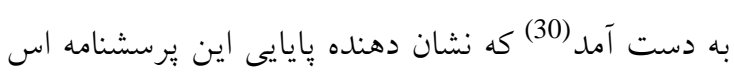

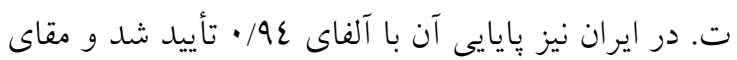

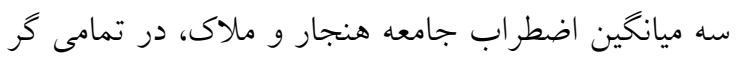

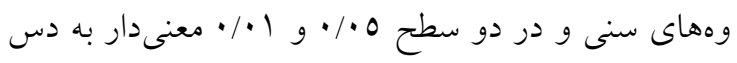

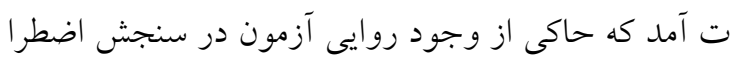

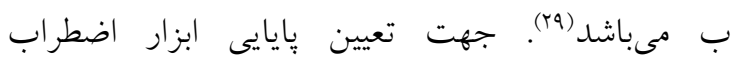
Spielberger

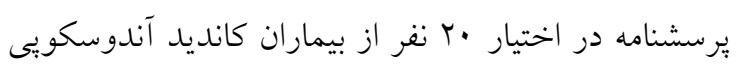

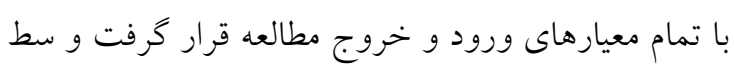

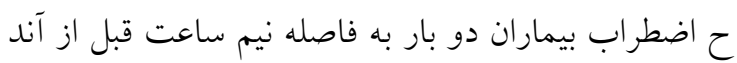

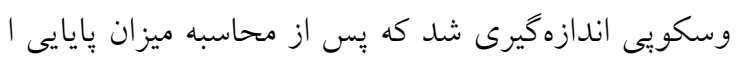

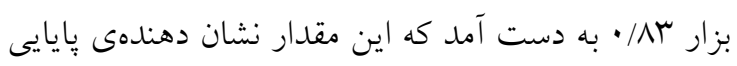
مناسب ابزار است.

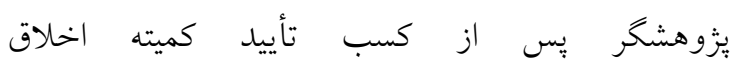
(IR.GUMS.REC.1396.462) و فناورى دانشخاه علوم يزشكى گيلان و ثبت طرح در مركز

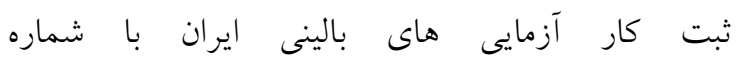
IRCT20180303038934N1 لازم با ورود به محيط يُزوهش (بخش آندوسكويى مركز

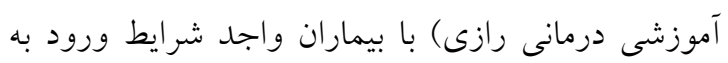

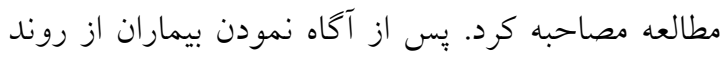

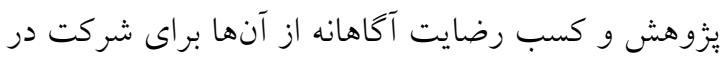

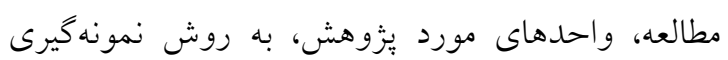


نتايج حاصل از مطالعه نشان داد كه ميانخين سنى بيماران در اين مطالعه 17/VO

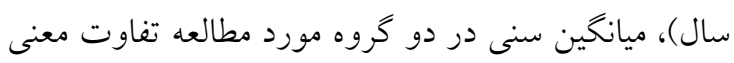

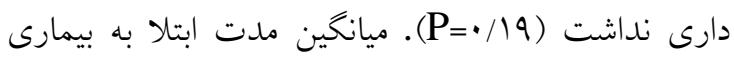

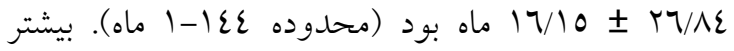

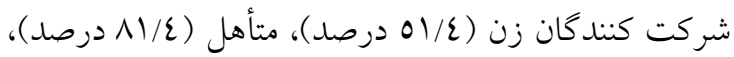

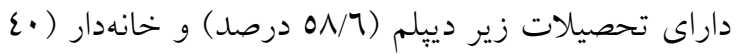
درصد) بودند. در مورد علائم بيماران مر اجعهكننده در اين

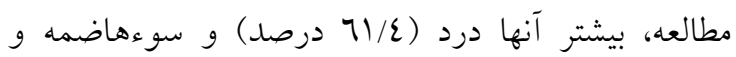
سوزش سر دل (NO/V درصد) را ذكر كرده بودند. N/7 درصد بيماران مصرف سيگار را كزارش كردند. از نظر متغيرهاى ذكر شده دو كروه مداخله و بِلاسبو از نظر آمارى

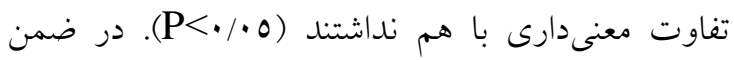
\& O/V درصد بيماران سابقه بسترى قبلى در بيمارستان را

$$
\text { ذكر كردند (جدول شماره ()). }
$$

روغن سوياى بدون بو بر روى گلوله ينبهاى جكانده شد

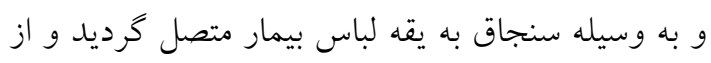

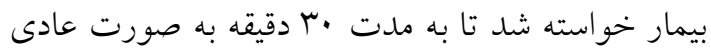

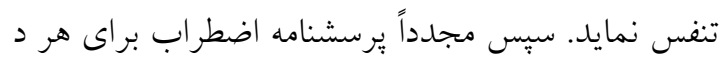

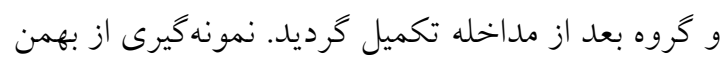

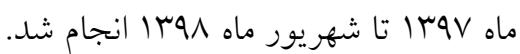

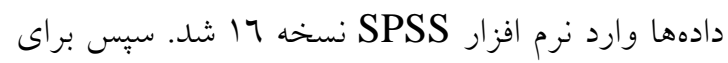
تجزيه و تحليل متغيرهاى فردى اجتماعى و سطح اضطرا

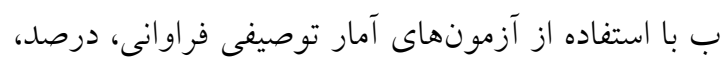

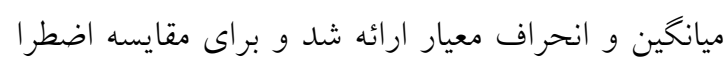

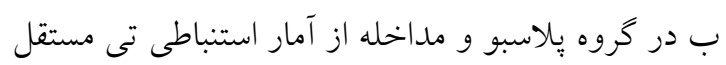

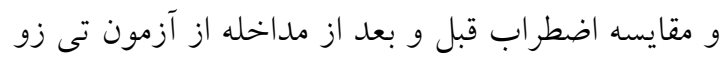

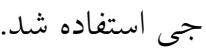

جدول شماره ا: اطلاعات جمعيت شناختى نمونههاى مورد يزوهش در خَروه مداخله و پيلاسبو

\begin{tabular}{|c|c|c|c|c|c|c|c|c|}
\hline \multirow[t]{2}{*}{ معنى دارى } & \multicolumn{2}{|c|}{ كروه يلاسبو } & \multicolumn{2}{|c|}{ كروه مداخله } & \multirow{2}{*}{ درصد } & \multirow[t]{2}{*}{ تعداد } & \multirow{2}{*}{\multicolumn{2}{|c|}{ متغيرها }} \\
\hline & درصد & تعداد & درصد & تعداد & & & & \\
\hline$* \mathrm{P}=\cdot / \pi \mu q$ & $\varepsilon 0 / V$ & 17 & $O V / I$ & $r$. & $01 / \varepsilon$ & ru & زن & \\
\hline$\chi^{2}=. / 910 \quad \mathrm{df}=1$ & $o \varepsilon / \Gamma$ & 19 & $\varepsilon r / 9$ & 10 & $\varepsilon \Lambda /\rceil$ & $r \varepsilon$ & مرد & جنسيت \\
\hline \multirow{3}{*}{$* * \mathrm{P}=1 / \cdots$} & $1 \varepsilon / \pi$ & 0 & $1 \varepsilon / \pi$ & 0 & $1 \varepsilon \pi$ & 1. & مجرد & \multirow{3}{*}{ وضعيت تأهل } \\
\hline & $\wedge$. & $r \wedge$ & $\Lambda r / q$ & rq & $\Lambda 1 / \varepsilon$ & ov & متأهل & \\
\hline & $0 / V$ & r & $r / 9$ & 1 & $\varepsilon / \mu$ & r & شده جدا يا مرده & \\
\hline \multirow{3}{*}{$\begin{array}{c}* \mathrm{P}=\cdot / 0 \wedge \mathrm{V} \\
\chi^{2}=1 / 70 \quad \mathrm{df}=r\end{array}$} & ov/l & $r \cdot$ & 7. & YI & $O \wedge / 7$ & $\varepsilon 1$ & زيردييلم & \multirow{3}{*}{ وضعيت تحصيل } \\
\hline & $r$. & V & $11 / \varepsilon$ & $\varepsilon$ & $10 / \mathrm{N}$ & 11 & دييلم & \\
\hline & $r r / q$ & $\wedge$ & $r N / T$ & 1. & rON & 11 & دانشخاهى & \\
\hline \multirow{6}{*}{$* * \mathrm{P}=\cdot / 77 \mathrm{~V}$} & $r \varepsilon / r$ & IT & $\varepsilon 0 N$ & 17 & $\varepsilon$. & ru & خانهدار & \multirow{6}{*}{ 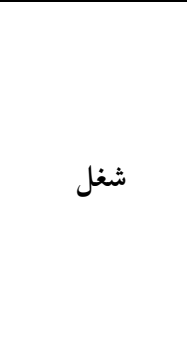 } \\
\hline & $11 / \varepsilon$ & $\varepsilon$ & $O / V$ & r & $\Lambda / 7$ & 7 & كارمند & \\
\hline & $1 \varepsilon / \mu$ & 0 & $O / V$ & r & 1. & v & كاركر & \\
\hline & $r_{1 / \varepsilon}$ & 11 & $r_{1 / \varepsilon}$ & 11 & $\mu_{1 / \varepsilon}$ & rr & آزاد & \\
\hline & . & . & $r / q$ & 1 & $1 / \varepsilon$ & 1 & بازنشسته & \\
\hline & $\Lambda / 7$ & r & $1 / 7$ & r & $\Lambda / 7$ & 7 & بيكار & \\
\hline \multirow{3}{*}{$* * \mathrm{P}=\cdot / 10 \varepsilon$} & $7 r / 9$ & rr & 7. & rl & $71 / 2$ & $\varepsilon r$ & درد & \multirow{3}{*}{ علايم بيمارى } \\
\hline & $r_{1 / \varepsilon}$ & 11 & r. & v & rON & 11 & سوزش سر دل & \\
\hline & $O / V$ & r & r. & v & $1 T / 9$ & 9 & ساير & \\
\hline$* \mathrm{P}=\cdot / \cdot \varepsilon$ & $7 T / 9$ & rr & $r \Lambda / T$ & 1. & $\varepsilon 0 / N$ & Mr & بله & \multirow{2}{*}{ سابقه بسترى } \\
\hline$\chi^{2}=\wedge / r \wedge 9 \quad \mathrm{df}=1$ & $r \mathrm{r} / \mathrm{l}$ & Ir & $V 1 / \varepsilon$ & ro & $0 \varepsilon \pi$ & ґ & خير & \\
\hline
\end{tabular}




\begin{tabular}{|c|c|c|c|c|c|c|c|c|}
\hline \multirow[t]{2}{*}{$* * \mathrm{P}=\cdot / \mathrm{V} r$} & & $\varepsilon$ & $O / V$ & $r$ & $\Lambda / 7$ & 7 & بله & \multirow{2}{*}{ سيكار كشيدن } \\
\hline & $\Lambda \Lambda / 7$ & ri & $9 \varepsilon / \pi$ & r & $91 / 2$ & $7 \varepsilon$ & خير & \\
\hline
\end{tabular}

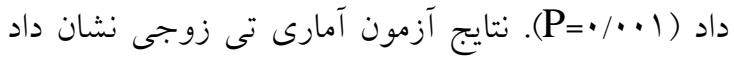

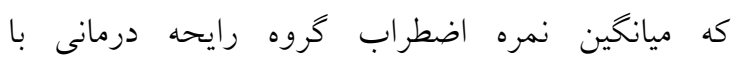

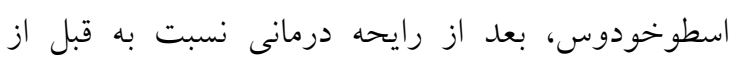

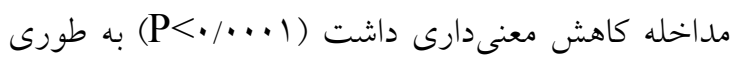

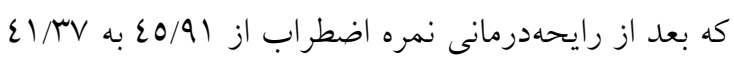

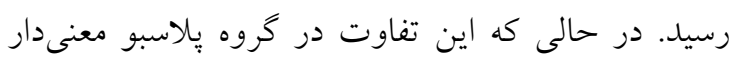

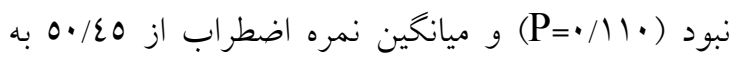
(ج/9 ع رسيد (جدول شماره ب).
نتايج نشان داد كه اضطراب بيماران در گروه مداخله و

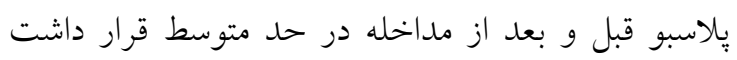

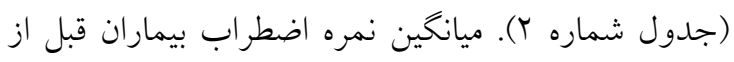

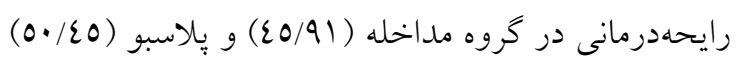
تفاوتى از نظر آمارى نداشت؛ اما پِّ از از انجام مداخله

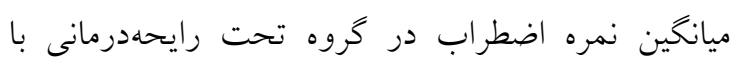

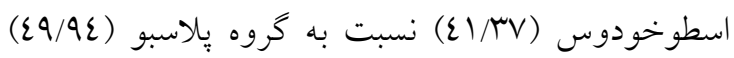

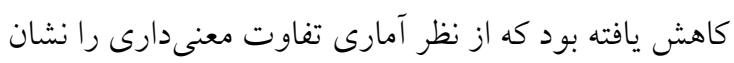

جدول شماره r: توزيع فراوانى اضطراب بيماران تحت آندوسكويى قبل و بعد از رايحه درمانى در دو كروه مداخله و يلاسبو

\begin{tabular}{|c|c|c|c|c|c|c|}
\hline \multicolumn{2}{|c|}{ يلاسبو } & \multicolumn{2}{|c|}{ مداخله } & \multicolumn{3}{|c|}{ متغير } \\
\hline درصد & ت تعداد & درصد & ت تعداد & & & \\
\hline$|V /|$ & 7 & $r T / q$ & $\wedge$ & خفيف & & \\
\hline $0 \varepsilon / r$ & 19 & $V 1 / \varepsilon$ & ro & متوسط & قبل از رايحه درمانى & اضط اب \\
\hline YN/T & 1. & $O / V$ & r & شديد & & \\
\hline$|V /|$ & 7 & $r V / l$ & $1 r$ & خفيف & & \\
\hline $0 \varepsilon / \Gamma$ & 19 & 7. & YI & متوسط & بعد از رايحه درمانى & \\
\hline YN/7 & 1. & $r / 9$ & 1 & شديد & & \\
\hline
\end{tabular}

جدول شماره ب: تعيين تفاوت اضطراب بيماران تحت آندوسكويى قبل و بعد از رايحه درمانى در دو تروه مداخله و پِلاسبو

\begin{tabular}{|c|c|c|c|c|c|}
\hline آزمون تى & بلاسبو & مداخله & \multicolumn{2}{|c|}{ متغير } & \multirow{4}{*}{ اضطراب } \\
\hline $\mathrm{P}=\cdot / \cdot \mathrm{V}$ & 0.120 & $20 / 91$ & ميانكين & \multirow{3}{*}{ قبل از رايحه درمانى } & \\
\hline $\mathrm{t}=-1 / N T r$ & $11 / 7 r$ & $9 / .7$ & انحر اف معيار & & \\
\hline $\mathrm{df}=\mathrm{u}$ & $1 / 97$ & 1/or & خطاى معيار & & \\
\hline $\mathrm{P}=\cdot / \cdot \cdot 1$ & $\varepsilon q / 9 \varepsilon$ & $\varepsilon 1 / \Gamma V$ & ميانكين & \multirow{3}{*}{ بعد از رايحه درمانى } & \\
\hline$t=-r / \varepsilon \varepsilon \Lambda$ & $\mid r / r$. & $\Lambda / \cdot \varepsilon$ & انحر اف معيار & & \\
\hline \multirow[t]{2}{*}{$\mathrm{df}=\mathrm{u}$} & $r / \cdot \Lambda$ & $1 / \pi 7$ & خطاى معيار & & \\
\hline & $\mathrm{P}=\cdot / 11$ & $\mathrm{P}=\cdot / \cdots \cdot 1$ & \multicolumn{2}{|c|}{ آزمون تى زوجى } & \\
\hline
\end{tabular}

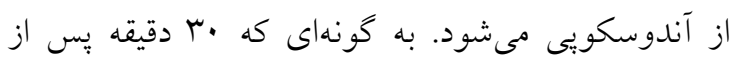

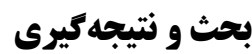

استشاق رايحه اسطوخودوس اضطراب بيماران تحت

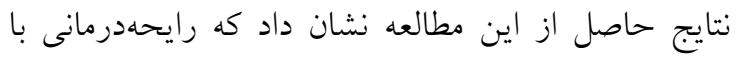
آندوسكويى نسبت به قبل از مداخله و رايحه درمانى كاهش رابه

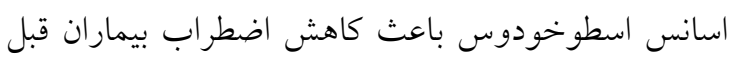


مر اجعه كننده به بيمارستان قائم مشهل، بيماران سه قطره از

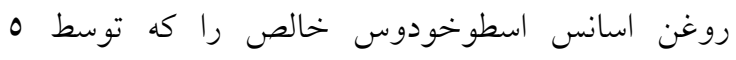

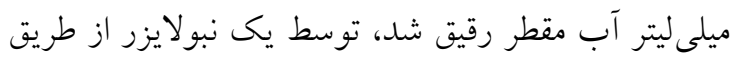
ماسك صورت به مدت ده دقيقه استنشاق كردند. نتايج نشان داد كه رايحهدرمانى با اسطوخودوس بر اضطراب

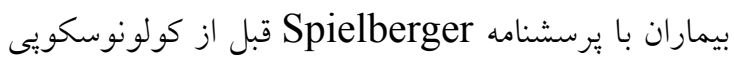

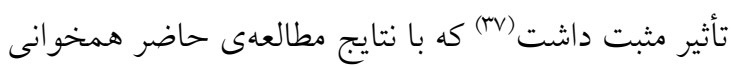

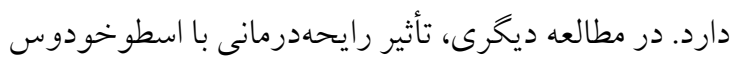

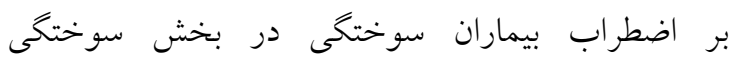

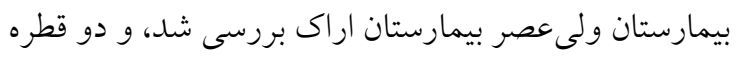
اسانس اسطوخودوس دو درصد روى دستمال ده در ده سانتىمترى و به فاصله •r سانتىمترى از بينى بيمار روى

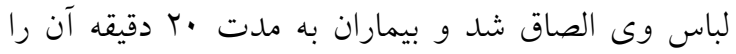

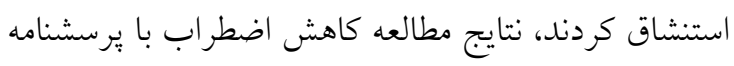
Spielberger نشان داد(17). در راستاى نتايج مطالعه حاضر، مطالعه مرور

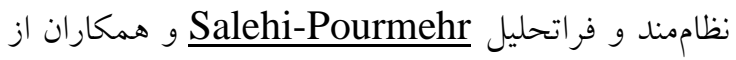

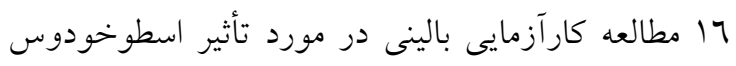

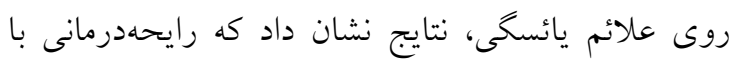

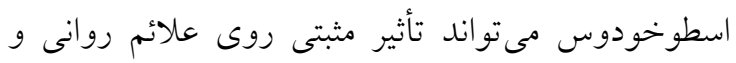

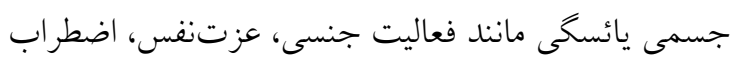

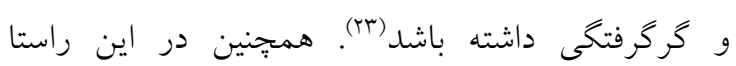

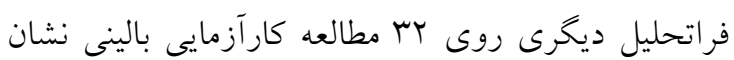

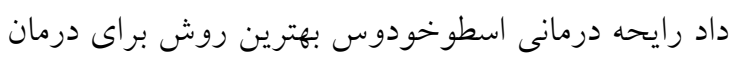
اضطراب در بين ساير روشهاى اسطوخودوس در كوتاه

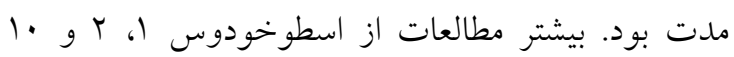

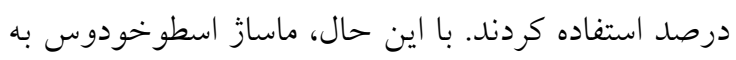

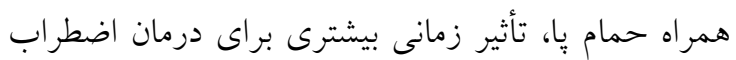

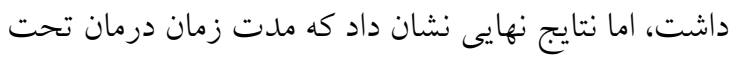

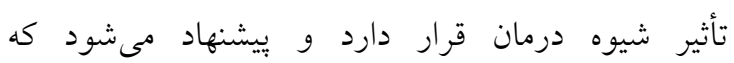
اسطوخودوس خوراكى (•^ ميلى گرم) به عنوان گزينه مطلوب در درمان طولانى مدت كتترل اضطراب در نظر كرفته شود (rr) (ب)
معنى دارى را نشان داد. اين يافته مىتواند حاكى از تأثير

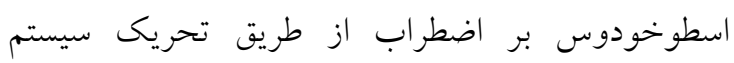
پاراسمياتيك بوده و با كاهش تعداد ضربان قلب، تنفس و و

$$
\text { فشار خون موجب آرامش مىشود (10). }
$$

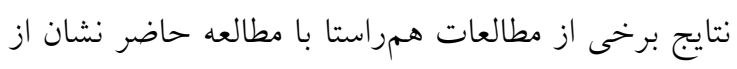

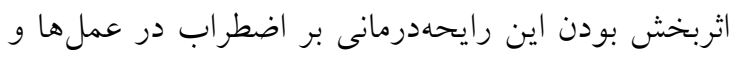

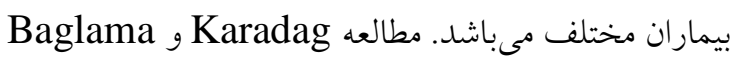
با هدف تعيين تأثير رايحهدرمانى اسطوخودوس بر ميزان مطان

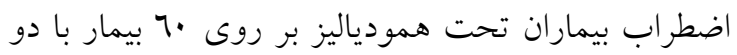
قطره اسطوخودوس دو درصد به مدت ·r دقيقه در تركيه نشان داد كه رايحهدرمانى به طور معنىدارى اضطراب

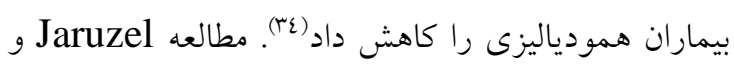
همكاران با هدف تأثير رايحهدرمانى اسطوخودوس باهي دارد

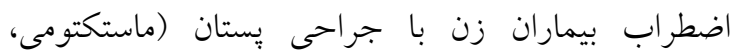

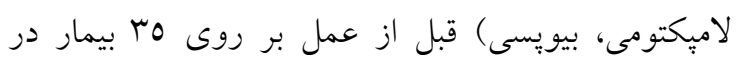

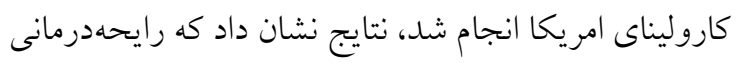

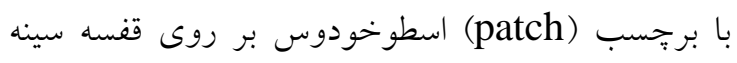

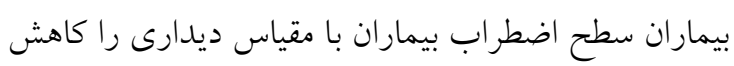

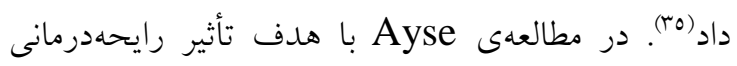

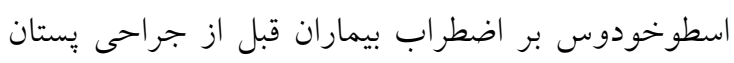

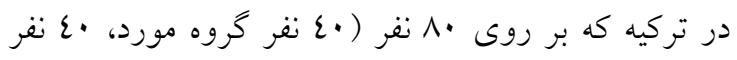

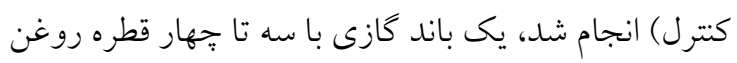

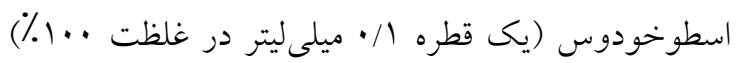
براى استنشاق •r دقيقه در روز عمل به بيماران داده شد.

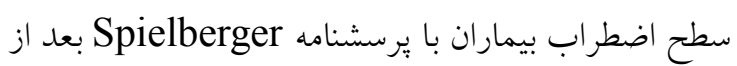

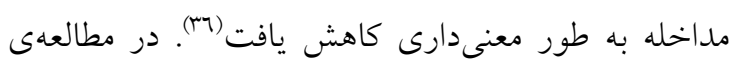

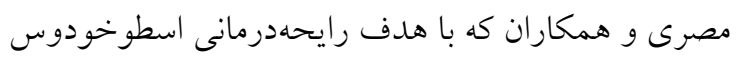

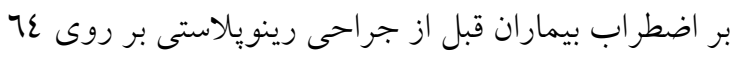

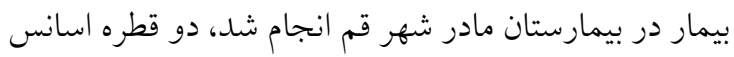

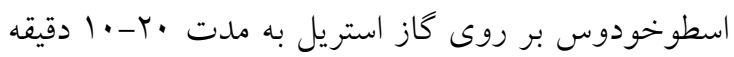
توسط بيماران استشاق شد. اين مطالعه نشان داد كه به روكان رايحهدرمانى با اسطوخودوس باعث كاهش اضطراب

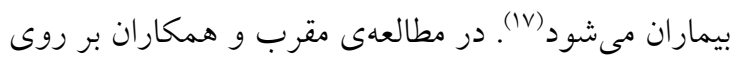

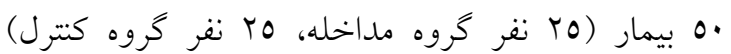


سالم بررسى شد، يعنى كسانى كه در شر ايط بيمارى و تحت

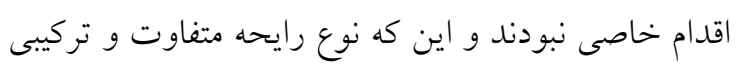
از جند رايحه مانند بهارنارنج بود و نحوه استشاق آن آن كاملاً

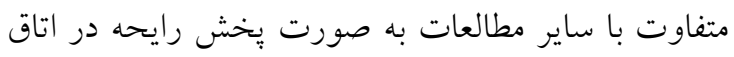

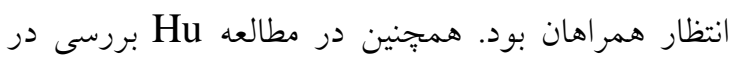

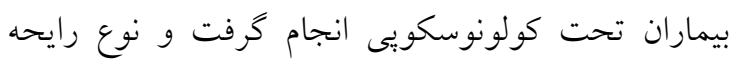
مورد استفاده نيز متفاوت با اسطوخودوس بود. در مطالعه

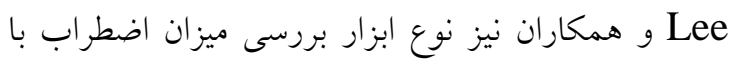

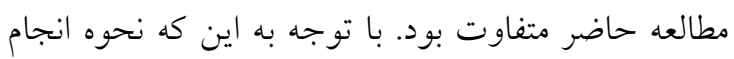

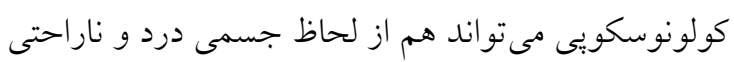

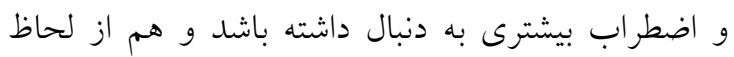

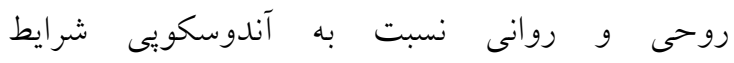
استرسآورترى را در يى دارد، شايد علت عدم تأثير

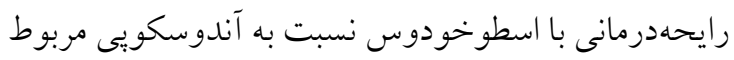

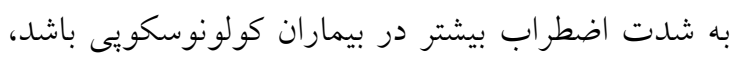

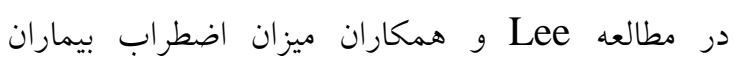

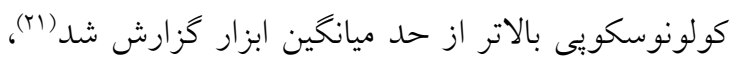

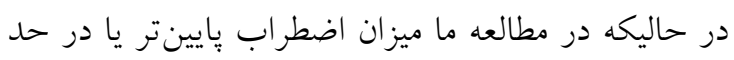
ميانخين ابزار بود.

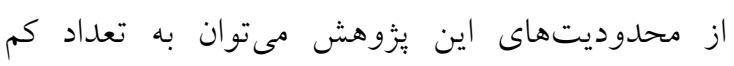

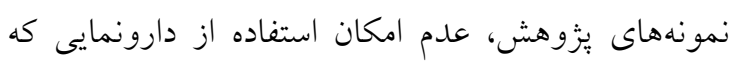

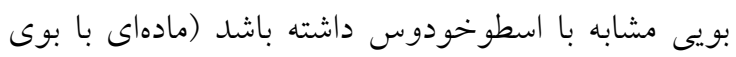

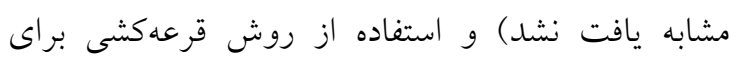

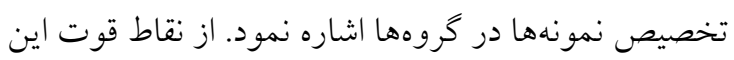

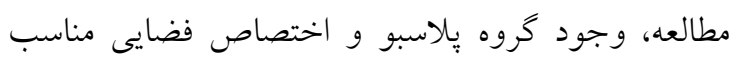
براى انجام مداخله (اتاقهايى مجزا براى دو كروه مداخله و پِاسبو در بخش آندوسكويى) بود.

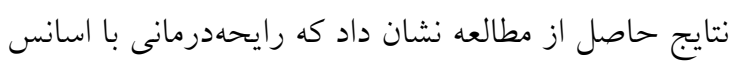
اسطوخودوس بر اضطر اب بيماران قبل از آندوسكويى مؤثر

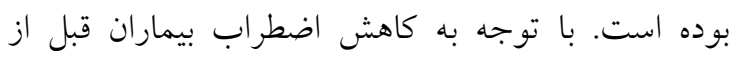

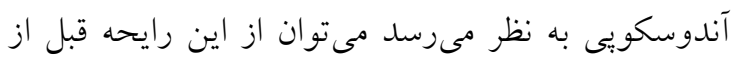

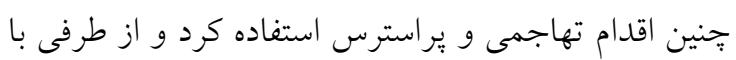

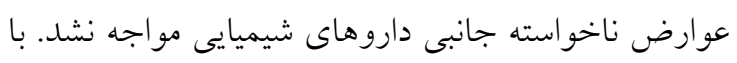
توجه به اينكه طب مكمل به طور روزافزون قسمتى از
يافتهاى بيشتر مطالعات همسو با مطالعه حاضر حاكى از

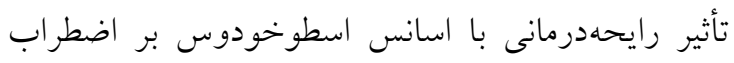

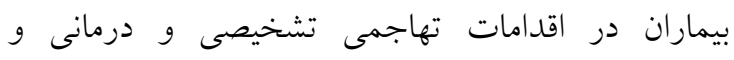
جراحىها مىباشد كه مىتواند در بررسىهاى بيشتر و و مراقبتهاى يرستارى به عنوان طب مكمل از آنان بهره كرفت. در حالى كه مطالعهى muzarreli در سوئيس كه به بررسى تأثير رايحهدرمانى اسطوخودوس بر اضطراب بيماران قبل

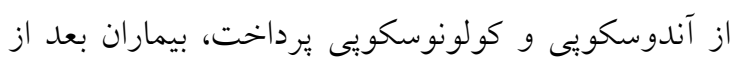

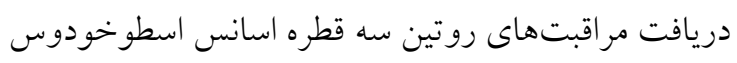

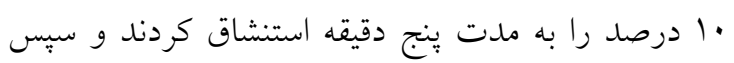

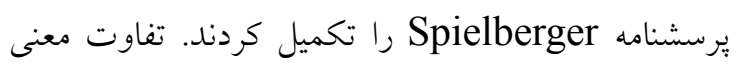
دارى بين سطح اضطراب بيماران قبل و بعد از مداخله

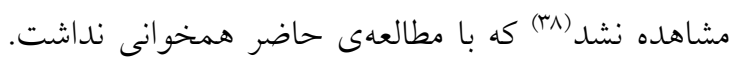
نتايج حاصل از مطالعه Holm و همكاران در امريكا نشان

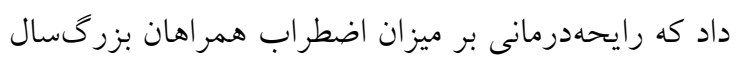

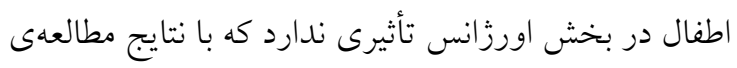

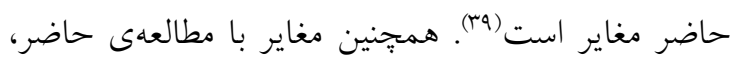
نتايج حاصل از مطالعه Hu و همكاران با هدف تأثنير

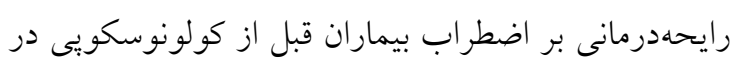

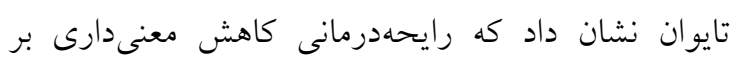

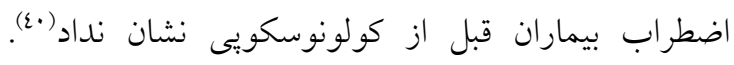

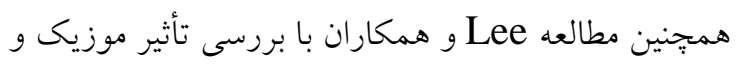

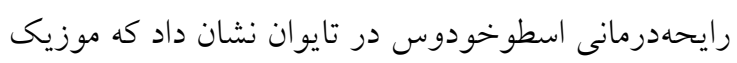
تأثير بيشترى بر اضطراب بيماران تحت تهويه مكانيكى إنى داني نسبت به رايحهدرمانى دارد (1).

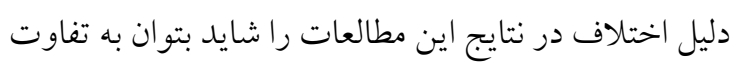

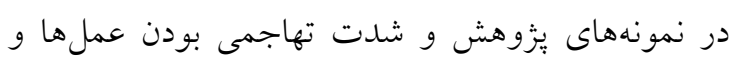

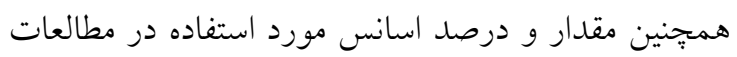
مختلف نسبت داد، به نحوى كه در مطالعهى muzarreli

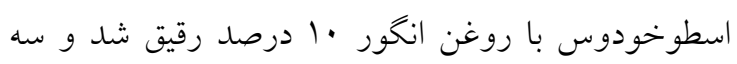

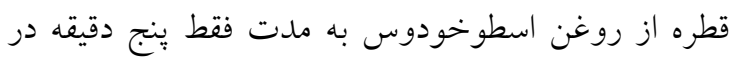

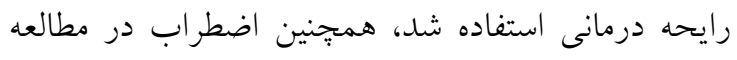

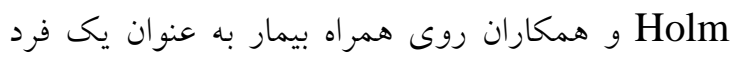




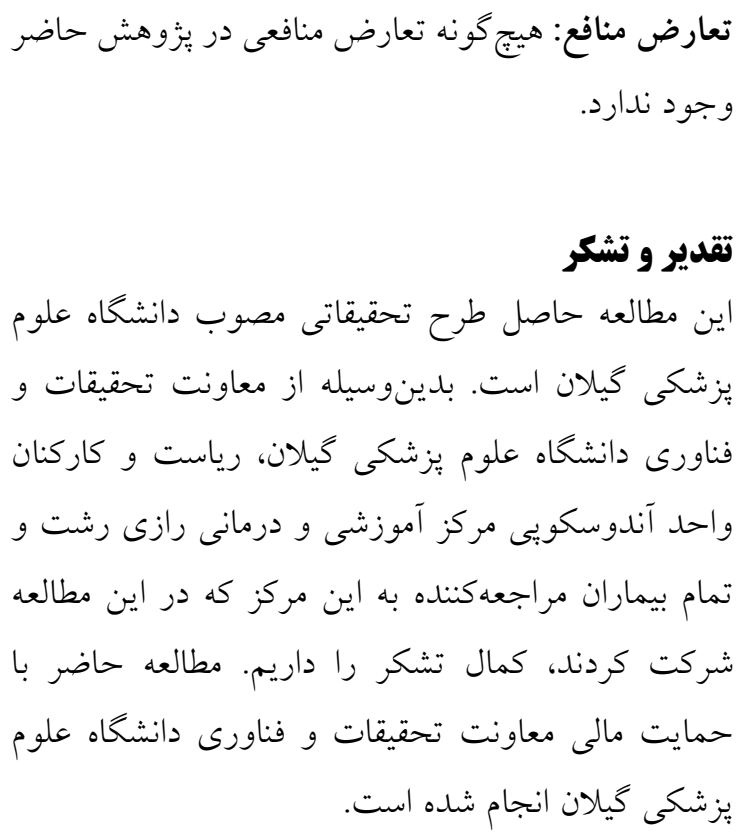

مراقبتهاى يرستارى را به خود اختصاص داده است، رايحهدرمانى با اسطوخودوس با توجه به هزينهى كم، ايمنى و سادگى آن، مىتواند به عنوان يكى از اقدامات مكمل براى كاهش اضطر اب در بيماران قبل از آندوسكويى بيشنهاد گردد. انجام مطالعات كارآزمايى بالينى شاهددار تصادفى شده براى بررسى تأثير رايحهدرمانى اسطوخودوس به طور مقايسهاى بر حسب مشخصات جمعيت شناختى مختلف و عوامل مرتبط با بيمارى مانند سابقه بسترى قبلى در بيماران تحت آندوسكويى بيشنهاد مى شود.

\section{References:}

1. Poursharifi H, Doshmanshekar M, Somi M, Hosseinynasab S. Evaluation of the effectiveness of different teaching methods on anxiety in patients referred for endoscopy. Govaresh. 2013;18(1):32-8. [Persian]

2. Sargin M, Uluer MS, Aydogan E, Hanedan B, Tepe Mİ, Eryılmaz MA, Ebem E, Özmen S. Anxiety levels in patients undergoing sedation for elective upper gastrointestinal endoscopy and colonoscopy. Medical Archives. 2016;70(2):112.

3. Maghaminejad F, Adib-Hajbaghery M, Jahangir S. Predicting Factors of Patients' Anxiety before Endoscopy. Iranian Journal of Psychiatric Nursing. 2017;4(6):22-9. [Persian]

4. Samson R. Effect of Video Assisted Teaching on Anxiety among Patients Undergoing Upper Gastro Endoscopy. Int J Health Sci Res. 2019;9(7):86-94.

5. Orujlu S, Hemmati-Maslakpak M. Effect of nursing interventions on anxiety and vital signs in patients undergoing endoscopy: a randomized clinical trial study. Journal of Clinical Nursing and Midwifery. 2014;3. [Persian]

6. Bice AA, Gunther M, Wyatt T. Increasing nursing treatment for pediatric procedural pain. Pain Management Nursing. 2014;15(1):365-79.

7. Seda PE, Van NO, Mehmet Koruk YP, Van OO, Gulfien MT. Effect of providing information to the patient about upper gastrointestinal endoscopy on the patient's perception, compliance and anxiety level associated with the procedure. Turk J Gastroenterol. 2011;22(1):10-7.

8. Orujlu S, Hemmati-Maslakpak M. Effect of nursing interventions on anxiety and vital signs in patients undergoing endoscopy: a randomized clinical trial study. J Clin Nurs Mid. 2014;3(3):3643.

9. Najafi Z, Taghadosi M, Sharifi K, Farrokhian A, Tagharrobi Z. The effects of inhalation aromatherapy on anxiety in patients with myocardial infarction: a randomized clinical trial. Iranian Red Crescent Medical Journal. 2014;16(8). [Persian]

10. Pourmovahed Z, Zare Zardini H, Vahidi AR, Jafari Tadi E. The effect of inhalation aromatherapy on anxiety level of the patients before coronary artery bypass graft surgery (CABG). Journal of Rafsanjan University of Medical Sciences. 2016;15(6):551-62. [Persian]

11. Tahmasbi H, Mahmoodi G, Mokhberi V, Hassani S, Akbarzadeh H, Rahnamai N. The impact of aromatherapy on the anxiety of patients experiencing coronary angiography. Zahedan J Res Med Sci. 2012;14(3):51-5. [Persian]

12. Heidari MR, Nateq M, Ebadi A. Aromatherapy from the perspective of traditional Iranian medicine and modern medicine. Journal of Islamic and Iranian Traditional Medicine. 2017;8(2):173-82. [Persian] 
13. Ali B, Al-Wabel NA, Shams S, Ahamad A, Khan SA, Anwar F. Essential oils used in aromatherapy: A systemic review. Asian Pacific Journal of Tropical Biomedicine. 2015;5(8):60111.

14. Yaghoobi K, Kaka GR, Davoodi S, Ashayeri H. Therapeutic effects of Lavandula angustifolia. Journal of Gorgan University of Medical Sciences. 2016;17(4):1-9. [Persian]

15. Yazdkhasti M, Pirak A. The effect of aromatherapy with lavender essence on severity of labor pain and duration of labor in primiparous women. Complementary therapies in clinical practice. 2016;25:81-6.

16. Safarabadi M. Investigation on the effectiveness inhalation aromatherapy with Lavender essential oil on the anxiety of patients with burns. Complementary Medicine Journal. 2016;6(3):1583-91. [Persian]

17. Mesri M, Hossieni SM, Heidarifar R, Mirizade M, Forozanfar MJ. Effect of lavender aromatherapy on anxiety and hemodynamic changes: A randomized clinical trial. Qom University of Medical Sciences Journal. 2017;10(12):69-76. [Persian]

18. Hosseini S, Heydari A, Vakili M, Moghadam S, Tazyky S. Effect of lavender essence inhalation on the level of anxiety and blood cortisol in candidates for open-heart surgery. Iranian journal of nursing and midwifery research. 2016 1;21(4):397. [Persian]

19. Bekhradi R, Vakilian K. The effect of lavender aromatherapy on test anxiety in female students. Current Women's Health Reviews. 2016;12(2):137-40.

20. Kasper S, Möller HJ, Volz HP, Schläfke S, Dienel A. Silexan in generalized anxiety disorder: investigation of the therapeutic dosage range in a pooled data set. Int Clin Psychopharmacol. 2017;32(4):195-204.

21. Lee CH, Lai CL, Sung YH, Lai MY, Lin CY, Lin LY. Comparing effects between music intervention and aromatherapy on anxiety of patients undergoing mechanical ventilation in the intensive care unit: a randomized controlled trial. Quality of Life Research. 2017 J;26(7):1819-29.

22. Sayed AM, Morsy S, Tawfik GM, Naveed S, Minh-Duc NT, Hieu TH, Ali ZA, Shinkar A, Doheim MF, Hashan MR, Huy NT. The best route of administration of lavender for anxiety: a systematic review and network meta-analysis. General Hospital Psychiatry. 2020;64:33-40.

23. Salehi-Pourmehr H, Ostadrahimi A, Ebrahimpour-Mirzarezaei M, Farshbaf-Khalili A. Does aromatherapy with lavender affect physical and psychological symptoms of menopausal women? A systematic review and meta-analysis. Complem Therap Clin Practice. 2020 20:101150.

24. Stanley PF, Wan LF, Karim RA. A Randomized Prospective Placebo-Controlled Study of the Effects of Lavender Aromatherapy on Preoperative Anxiety in Cataract Surgery Patients. Journal of PeriAnesthesia Nursing. 2020 Mar 13.

25. Abbaszadeh R, Tabari F, Asadpour A. The Effect of Lavender Aroma on Anxiety of Patients Having Bone Marrow Biopsy. Asian Pacific Journal of Cancer Prevention. 2020;21(3):771-5.

26. Spielberger CD, Gorsuch RL, Lushene RE. Manual for the state-trait anxiety inventory. 1970.

27. Fayazi S, Babashahi M, Rezaei M. The effect of inhalation aromatherapy on anxiety level of the patients in preoperative period. Iranian journal of nursing and midwifery research. 2011;16(4):278. [Persian]

28. Kahangi L, Moeini M, Babashahi M. The effects of reflexology on anxiety levels before coronary artery bypass graft surgery. Journal of Research in Behavioural Sciences. 2012;9(5):0. [Persian]

29. Mahram B. Validation of Eshpil berger anxiety test in Mashhad. Tehran: University of Education. 1994..

30. Spielberger CD, Gorsuch RL. State-trait anxiety inventory for adults: Manual and sample: Manual, instrument and scoring guide: Consulting Psychologists Press; 1983

31. Bates CK, Carroll N, Potter J. The challenging pelvic examination. J Gen Int Med. 2011;26(6):6517.

32. Tugut N, Demirel G, Baser M, Ata EE, Karakus S. Effects of lavender scent on patients' anxiety and pain levels during gynecological examination. Complementary therapies in clinical practice. 2017;28:65.

33. Rajai N, Sajadi SA, Teymouri F, Zareiyan A, Siavoshi S, Malmir M. The Effect of aromatherapy with lavender essential oil on anxiety and stress in patients undergoing coronary artery bypass graft surgery. signs. 2016;10:23. 
34. Karadag E, Baglama SS. The effect of aromatherapy on fatigue and anxiety in patients undergoing hemodialysis treatment: a randomized controlled study. Holistic Nursing Practice. 2019;33(4):222-9.

35. Jaruzel CB, Gregoski M, Mueller M, Faircloth A, Kelechi T. Aromatherapy for preoperative anxiety: A pilot study. Journal of Perianesthesia Nursing. 2019;34(2):259-64.

36. Beyliklioğlu A, Arslan S. Effect of lavender oil on the anxiety of patients before breast surgery. Journal of Perianesthesia Nursing. 2019;34(3):587-93.

37. Mogharab M, Ayoubzadeh K, Hosseini SM, Sharifzadeh G. The effects of inhalation of aromatherapy with lavender on anxiety amongst patients undergoing colonoscopy. Mod Care J. 2016;13(1):e9457. [Persian]

38. Muzzarelli L, Force M, Sebold M. Aromatherapy and reducing preprocedural anxiety: A controlled prospective study. Gastroenterology nursing: the official journal of the Society of Gastroenterology Nurses and Associates. 2006;29(6):466-71.

39. Holm L, Fitzmaurice L. Emergency department waiting room stress: can music or aromatherapy improve anxiety scores?. Pediatric emergency care. 2008;24(12):836-8.

40. Hu PH, Peng YC, Lin YT, Chang CS, Ou MC. Aromatherapy for reducing colonoscopy related procedural anxiety and physiological parameters: a randomized controlled study. Hepatogastroenterology. 2010;57(102):1082. 